\title{
Bioinformatics approaches to understand the interactions between the SARS corona Virus (SARS- CoV19) with stranded drugs of anti-retro viral treatment, Influenza and Malaria.
}

\section{Santhoshi Rani Nanchari}

national institute of nutrition

Shyam perugu ( $\square$ shyamperugu@nitw.ac.in )

National Institute of technology

\section{Research}

Keywords: COVID19, SARS-CoV, Spike S1, molecular docking

Posted Date: April 5th, 2020

DOI: https://doi.org/10.21203/rs.3.rs-20010/v1

License: (a) (1) This work is licensed under a Creative Commons Attribution 4.0 International License. Read Full License 


\section{Abstract}

Background: Severe acute respiratory syndrome (SARS) is highly contagious disease caused by virus COVID19. The first case is reported in Wuhan, China, with rapid spreading all over the world and the rate of mortality is also high. SARS-CoV and another human coronavirus, HCoV-NL63 has large spike protein $(\mathrm{S})$ on the virion surface mediates both cell attachment and membrane fusion with receptor sites present on host cell-surface zinc peptidase, angiotensin-converting enzyme 2 (ACE2).

Methodology: In the present study, molecular docking studies have been carried out to assess the interaction between the novel corona virus protein COVID19 with stranded drugs used for influenza, antiretro viral therapy and malaria drugs by using Accelerys discovery studio 2.5 , followed by analysis of data. The present study will help to design the drugs against the corona virus and understand the mode of treatment for SARS.

Results: All the four-protein receptor of COVID 19 proteins at particular amino acid position binds to the $\mathrm{NH}$ and $\mathrm{H}$ atom of anti-retro viral therapy drugs (Atazanavir, Doravirine, Emitricitabine, Entravirine, Raltegravir, Tenofavir Disproxil, and Zidovudin) and anti-malaria drug (Hydroxy chloroquine) with less hydrogen bond distance with maximum docking scores which indicates that these compounds can acts against the COVID19 virus. Gene mania network help to design the novel drugs and diagnosis.

Conclusions: This is first report to show the molecular docking interaction between the COVID19 protein with stranded drugs of anti -viral treatment. anti-viral drugs Atazanavir, Doravirine, Emitricitabine, Entravirine, Raltegravir, Tenofavir Disproxil, and Zidovudin and malaria drug Hydroxy chloroquine has more strong binding with COVID19 protein receptors.

\section{Background}

Coronaviruses affects the health threats to humans and animals with symptoms of cough, sneezing, fever and fatigue. As of now, two-different coronaviruses are known pathogens to humans, SARS-CoV and MERS-CoV. SARS-CoV caused the SARS epidemic in 2002 to 2003, with over 8,000 infections and a fatality rate of $10 \%$. MERS-CoV emerged from the Middle East in 2012. As of 16 October 2014, MERS-CoV had caused 877 infections with a fatality rate of 36\%(9)[1]. Suddenly the SARS-CoV infections are raised in Wuhan China, spreads to all over the world leading to the lethal deaths(3)[2]. According to the WHO report, around 89,000 cases were found to be COVID19 positive in China. In India, according to the report by the Ministry of Health and Family Welfare, the pandemic spread of COVID19 from china to India on 30th January 2020. As of now (23rd march, 2020), the COVID-19 positive cases have reached to 415 and death cases were reported to be 7, after Maharashtra, Kerala, Noida, and Karnataka reported fresh cases (https://www.mohfw.gov.in/). Several studies are confirming that COVID19 infected patients with comorbidities like has hypertension, diabetes mellitus.... etc have higher rate of death. Study by Qin et al included1099 patients with confirmed COVID-19 positive, of whom 173 had severe disease with comorbidities of hypertension ( $23 \cdot 7 \%)$, diabetes mellitus $(16 \cdot 2 \%)$, coronary heart diseases $(5 \cdot 8 \%)$, and 
cerebrovascular disease (2.3\%). The death rate was also found to be very high(12)[3]. The principle mechanism of coronavirus binds to the host cells is, it has spike (S) glycoproteins that promote the viral entry into host cells $(7,10,16,22)[4-7]$. The spike proteins contain two distinctive domains, the C-terminal domain (S1-CTD) and the N-terminal domain (S1-NTD), both of which can plays role as receptor-binding domains (RBDs) (9) [1]. S1-CTDs and S1-NTDs from three major coronavirus genera recognize at least four protein receptors and three sugar molecules/ receptors and demonstrate a complex receptor recognition pattern $(9,16)[1,6]$. Several studies are demonstrating that SARS-CoV-2 Spike S1 uses angiotensin converting enzyme receptor 2 (ACE2) to enter cells and that the receptor-binding domains of SARS-CoV-2 S1 and SARS-CoV S bind with similar affinities to human ACE2 and transmembrane Serine Protease 2 (TMPRSS2) correlating with the efficient spread of SARSCoV-2 among human epithelial cells i.e. lungs $(2,5,19-21,23)[8-13]$. We might think that, after the viral entry into the host cells, virus may be continuously replicate and lysis the host cells, then spreads to the other cells or this RNA virus may block the host metabolic machinery. The SARSCoV-2 Spike glycoprotein harbours a furin cleavage site at the boundary between the S1/S2 subunits, which is processed during biogenesis and sets this virus apart from SARS-CoV and SARS-related CoVs. Cryo-EM structures of the SARSCoV-2 Spike ectodomain trimer, providing a blueprint for the design of vaccines and inhibitors of viral entry(16)[6]. Finally, SARS-CoV S murine polyclonal antibodies potently inhibited SARSCoV-2 S mediated entry into cells, indicating that cross-neutralizing antibodies targeting conserved Spike epitopes can be elicited upon vaccination(16)[6]. Right now, there is no particular treatment for COVID19 positive patients, however doctors are treating the patients with anti-retroviral therapy, swine flu and influenza flu therapy. The antiviral drug, called Favipiravir or Avigan, showed positive response in clinical trials involving 340 individuals in Wuhan and Shenzhen, said by Zhang Xinmin, of China's science and technology ministry (https://www.genengnews.com/news/coronavirus-gileads-remdesivir-begins-trials-as-researchers-publishpositive-in-vitro-results/.) Anti-retro-viral drugs are using for the treatment of HIV positive patients such as nucleoside (lamivudine, zidovudine, didanosine, emtricitabine, tenofovir, stavudine and abacavir) and non-nucleoside (efavirenz, nevirapine, delavirdine, etravirine and rilpivirine) reverse transcriptase inhibitors block the reverse transcription(4)[14]. Integrase inhibitors block the viral DNA into host DNA by blocking integrase (raltegravir, elvitegravir and dolutegravir) $(11,14,15)[15-17]$ and protease inhibitors(saquinavir, ritonavir, nelfinavir, indinavir and amprenavir) block the viral protease enzyme required for mature virions production $(6,18)[18,19]$, CCR5 (Chemokine receptor type 5) antagonist, Fusion inhibitor (Enfuvirtide) also block the viral entry into the host(1)[20]... etc (13)[21]. We are assessing the interactions between COVID19 viral protein and the anti-viral drugs with used for flu symptoms such Tamiflu (oseltamivir) and Relenza (zanamivir), Rapivab (peramivir) and Xofluza (baloxavir marboxil)... ...etc and anti-retro viral therapy drugs such as Atazanavir or ATV (Reyataz), Darunavir or DRV (Prezista), Fosamprenavir or FPV (Lexiva), Indinavir or IDV (Crixivan) Lopinavir + ritonavir, or LPV/r (Kaletra), Nelfinavir or NFV (Viracept), Ritonavir or RTV (Norvir), Saquinavir or SQV (Invirase, Fortovase), Tipranavir or TPV (Aptivus), Abacavir, or ABC (Ziagen), Didanosine, or ddl (Videx), Emtricitabine, or FTC (Emtriva), Lamivudine, or 3TC (Epivir), Stavudine, or d4T (Zerit), Tenofovir alafenamide, or TAF (Vemlidy), Tenofovir disoproxil fumarate, or TDF (Viread), Zidovudine or ZDV (Retrovir) Delavirdine or DLV (Rescripor), Doravirine, or DOR (Pifeltro), 
Efavirenz or EFV (Sustiva), Etravirine or ETR (Intelence), Nevirapine or NVP (Viramune), Rilpivirine or RPV (Edurant). These protein- ligand interaction will help the patients with better therapeutic options.

\section{Methods}

In the present study, we have planned to study the molecular docking interaction between viral protein COVID19 and ligands of retroviral and malaria therapeutic drugs.

Molecular docking: Molecular docking analysis was performed to know the interaction between the COVID19 virus with antiviral drugs used for common flu symptoms, malaria therapy and also with antiretroviral therapy, currently using for treatment of SARS-CoV2. All the FDA approved drugs Atazanavir, Doravirine, Emtricitabine, Etravirine, Hydroxychloroquine, Raltegravir, Tenofavir Disoproxil, Tipranavir, Zidovudine were downloaded from the Pubchem database and molecular energy was minimized using the energy minimization module of Discovery Studio version 4.1 (Accelrys Inc., San Diego, CA, USA) under the chemistry at Harvard Macromolecular Mechanics (CHARMM) force field. Crystal Structures of COVID19 main protease in complex with Z18197050 (5r80), Nsp9 replicase protein of COVID-19 (6W4B), COVID19 main protease with unliganded active site (6Y84), coronavirus attachment to sialic acid receptorsApo-HCoV-OC43 S (6OHW) etc are selected for analysis. The crystal structures were downloaded from Protein Data Bank (PDB) (http://www.rcsb.org) and are listed in (Table 1, 2, 3 and 4). The structure preparation and correction of protein were performed using Discovery Studio 4.1 suite. The target protein file was prepared by removing the structural water molecule, hetero atoms and co-factors by leaving only the residues associated with protein by using Accelerys Discovery Studio 4.1 (ADS) tool was used to prepare target protein file addition of polar hydrogen's to the macromolecule, an essential step to correct the calculation of partial charge by keeping all other values as default(8)[22]. The molecular docking was performed using Ligand Fit module and obtained results were scrutinized based on highest dock score and number of $\mathrm{H}$-bonds by SS Viewer. The bond distance between ligand residues and protein receptor i.e. $A^{\circ}>3.10$ consider to be significant, which has stronger interactions and binding affinity to be high. $A^{\circ}$ $<3.10$ was ignored from the docking studies (Table 1, 2, 3 and 4).

Genemania: It is a free access online tool for predict genes and proteins interaction based on previous literature support(17)[23]. In the present study we will assess the structural analysis of COVID19 and their interaction with other molecules or receptors present on the host cell surface. In the present study the ACE2 and TMPRSS2 proteins interaction with other proteins, co expression of these proteins, shared protein domains, genetic interactions with other genes, colocalization of these genes, genes which are involved in similar pathway is studied by Genemania(17)[23]. This will help to predict the ACE2 and TMPRSS2 proteins interaction with other proteins and it also helps in studying the molecular mechanisms of COVID 19 positive cases because elevated ACE2 and TMPRSS2 proteins are associated with COVID 19 viral entry (Fig 5 and 6). Understanding the molecular mechanism after viral entry will 
defiantly help in diagnosis (RT-PCR analysis for Co- expression markers) and to the design the novel drugs.

\section{Results}

Molecular docking results were identified basis on the ideal interacted ligands were scrutinized based on the greatest ligand binding poses were identified using the low binding energy, high docking score and the number of $\mathrm{H}$-bonding, hydrophobic interactions at receptor site. In the Table.1, 2, 3, 4 represents the docking score, Hydrogen bond distance and interacting atoms. All the compounds were found to be buried. Molecular docking interactions with receptor [Crystal Structure of COVID-19 main protease in complex with Z18197050 (5r80)] and ligand (Stranded drugs) was represented in table (1 to 4). $\mathrm{NH}$ (amino groups) atom of Doravirine, Emtricitabine, Raltegravir and Tenofavir Disproxil was found to strongly binds to COVID-19 protease complex at THR25-OG1 (H-bond Distance $\left.A^{\circ}=2.55\right)$, THR190-O $\left(A^{\circ}=\right.$ 2.96), GLU166-O $\left(A^{\circ}=2.78\right)$ and GLU166-O $\left(A^{\circ}=2.25\right)$ respectively. Among these Doravirine and Tenofavir Disproxil has strong binding affinity with COVID 19 protease complex with docking score is -86.864 and $-85.375 \mathrm{Kcal} / \mathrm{mol}$ respectively (table 1 and Fig 1 ). Another receptor of Nsp9 replicase protein of COVID-19 (6W4B)] and ligand (Stranded drugs) interaction showed that nitrogen group (NH) of stranded drugs with receptor molecule 6W4B with less hydrogen bond [Atazanavir (GLN50-NE2 =2.74 and MET1-0=2.98), Doravirine(THR35-OD1=2.86), Entravirine (SER6-0=2.61 and VAL8-0=2.84), Hydroxy chloroquine (Thr68-OG1=2.81), Raltegravir (ARG56=2.74 and ASP27OD1=2.77), Tenofavir Disproxil(PRO58-0=2.61) and Zidovudine(PRO58-0=2.59)] respectively(table 2 and Fig 2).

$\mathrm{NH}$ atom of selected ligands binds effectively to the active site of COVID19 protease complex (6Y84) at different amino acids positions with less hydrogen bond distance [Doravirine (PHE185-0= 2.97, PHE185$\mathrm{O}=2.98, \mathrm{ASP} 187-\mathrm{O}=2.92$ ), Emtricitabine (SER144-OG=2.91, CYS145-N=2.90), Etravirine (SER144$\mathrm{OG}=2.63$ ), Zidovudine (PHE140-O=2.66, GLY143-N=2.73 and CYS145-N=2.90)] (table 3 and Fig 3).

The receptor molecule of Coronavirus attachment to sialic acid receptors- Apo-HCoV-OC43 (6OHW)] high affinity binding to $\mathrm{NH}$ atom of drugs such Doravirine(ASN133-ND2=2.95), Emtricitabine (SER196$\mathrm{OG}=2.98$; GLN165-OE1 = 2.60), Entravirine(GLN165-OE1=2.57), Raltegravir(GLY193-N=2.74; THR192$\mathrm{N}=2.66$ ), Tenofavir Disproxil (VAL194-O=2.64; VAL194-O=2.85). (Table 4 and Fig 4). Hydrogen molecule present on the Tipranavir and Zidovudine also binds to the 60HW protein molecule at ASN167-ND2 and ASP191-OD1 with less hydrogen bond distance 2.98 and 2.66 respectively. Lesser the hydrogen bond distance between the protein molecules and ligands of stranded drugs indicate that higher the affinity, stability of bonding is more and specific. Hence in these molecular docking studies are showing that the i.e., Atazanavir, Doravirine, Emtricitabine, Etravirine, Hydroxychloroquine, Raltegravir, Tenofavir Disoproxil, Tipranavir, Zidovudine are interacting with corona virus (COVID 19) receptor or protein complexes. These drugs might be better useful for the treatment of SARS-COV19 disease. 
Genemania: It is a literature-based web interface tool for prediction genes interaction with other molecules and protein -protein interaction i.e. is protein data base and gene data base. Several studies are suggested that after COVID 19 viral infection ACE2 and TMPRSS2 proteins are upregulated, leads to the acqute respiratory syndrome. Genemania results are suggested that ACE2 physically interacts with angiotensin (AGT), Catalase (CAT), inositol-3-phosphate synthase 1 (ISYNA1), angio associated migratory cell protein (AAMP) and ghrelin and obestatin prepropeptide (GHRL), Co-expression with CAT, annexin A13 (ANXA13), solute carrier family 10 member 2 (SLC10A2), glycerol kinase (GK), fyn related Src family tyrosine kinase (FRK), GHRL, trehalase (TREH), glutathione S-transferase alpha 3(GSTA3), transmembrane protein 27 (TMEM27), angio associated migratory cell protein (AAMP), cadherin related family member 2(CDHR2), hook microtubule tethering protein 1 (HOOK1).... etc. Co-localize with solute carrier family 12 member 6(SLC12A6), GK, fyn related Src family tyrosine kinase (FRK), HOOK1...etc, Shared protein-protein domains other molecules like ACE, TMEM27, ...etc. still pathway of ACE2 was not understood (Fig 5). TMPRSS2 protein co-express with kallikrein related peptidase 2, 3 and 4 (KLK2, KLK3 and KLK4), androgen receptor (AR), solute carrier family 37 member 1 (SLC37A1), acyl carrier protein (ACP), solute carrier family 45 member 3(SLC45A3), solute carrier family 6 member 4 (SLCA4), ...like molecules. It is co-localized with KLK3, KLK2, KLK4, AR, SLC44A4, phosphodiesterase 9A (PDE9A), SLC37A1, etc. TMPRSS2, KLK2, KLK3, AR, lysine demethylase 3A (KDM3A), PDE9A are in same pathway. TMPRSS2 is share protein-protein domains with KLK4, KLK2 and KLK3 (Fig 6). Genemania does show any interactions between the ACE2 and TMPRSS2 proteins. The common protein molecule found to interact with the ACE2 and TMPRSS2 are solute carrier family proteins. Understanding of these protein and gene network will help to design the drugs against COVID 19 virus.

\section{Discussion}

Understanding the mode of transmission, dynamics of the infection and evaluating the effectiveness of control measures is crucial for public health. Bioinformatics approaches of these present study will give the basic information for drug design, suitability of drugs and their efficiency of binding to the viral protein COVID19. The receptors of COVID 19 proteins $(6 \mathrm{~W} 4 \mathrm{~B}, 6 \mathrm{OHW})$ are shown good interactions with stranded drug molecules like Atazanavir, Doravirine, Emtricitabine, Etravirine, Hydroxychloroquine, Raltegravir, Tenofavir Disoproxil, Tipranavir, Zidovudine. The docking studies revealed that, all the FDA approved drugs exhibited excellent binding energies towards the receptor active sites. This protein (COVID19)-ligand (drugs) interaction will help the patient with successful treatment strategy and fast recovery from SARS. Patients and people need to understand the concept of prevention is better than cure is best way in the present situation for viral spread all over the world. Further sequence of the viral RNA will help to design the stranded drugs.

\section{Availability Of Data And Materials}

All data analysed during this current study are included within this article. 


\section{Abbreviations}

SARS: Severe acute respiratory syndrome

ACE2: angiotensin-converting enzyme 2

COVID-19: coronavirus disease 19

TMPRSS2: Transmembrane protease, serine 2

AGT: angiotensin

CAT: Catalase

ISYNA1: inositol-3-phosphate synthase 1

AAMP: angio associated migratory cell protein

GHRL: ghrelin and obestatin prepropeptide

ANXA13: annexin A13

SLC10A2: solute carrier family 10 member 2

GK: glycerol kinase

FRK: fyn related Src family tyrosine kinase

TREH trehalase

GSTA3: glutathione S-transferase alpha 3

TMEM27: transmembrane protein 27

AAMP: angio associated migratory cell protein

CDHR2: cadherin related family member 2

H0OK1: hook microtubule tethering protein 1

SLC12A6: solute carrier family 12 member 6

KLK2, KLK3 and KLK4: kallikrein related peptidase 2, 3 and 4

AR: androgen receptor

SLC37A1: solute carrier family 37 member 1 , 
ACP: acyl carrier protein

SLC45A3: solute carrier family 45 member 3

SLCA4: solute carrier family 6 member 4

SLC44A4: solute carrier family 44 member 4

PDE9A: phosphodiesterase 9A

KDM3A: lysine demethylase 3A

\section{References}

1. Bai, Y., H. Xue, K. Wang, L. Cai, J. Qiu, S. Bi, L. Lai, M. Cheng, S. Liu, and K. Liu. 2013. Covalent fusion inhibitors targeting HIV-1 gp41 deep pocket. Amino Acids 44:701-713.

2. Cao, Y., L. Li, Z. Feng, S. Wan, P. Huang, X. Sun, F. Wen, X. Huang, G. Ning, and W. Wang. 2020. Comparative genetic analysis of the novel coronavirus (2019-nCoV/SARS-CoV-2) receptor ACE2 in different populations. Cell discovery 6:11.

3. Chen, P., L. Mao, G. P. Nassis, P. Harmer, B. E. Ainsworth, and F. Li. 2020. Wuhan coronavirus (2019$\mathrm{nCoV})$ : The need to maintain regular physical activity while taking precautions. Journal of sport and health science 9:103-104.

4. Das, K., and E. Arnold. 2013. HIV-1 reverse transcriptase and antiviral drug resistance. Part 1. Current opinion in virology 3:111-118.

5. Hoffmann, M., H. Kleine-Weber, S. Schroeder, N. Kruger, T. Herrler, S. Erichsen, T. S. Schiergens, G. Herrler, N. H. Wu, A. Nitsche, M. A. Muller, C. Drosten, and S. Pohlmann. 2020. SARS-CoV-2 Cell Entry Depends on ACE2 and TMPRSS2 and Is Blocked by a Clinically Proven Protease Inhibitor. Cell.

6. Hughes, P. J., E. Cretton-Scott, A. Teague, and T. M. Wensel. 2011. Protease Inhibitors for Patients With HIV-1 Infection: A Comparative Overview. P \& T : a peer-reviewed journal for formulary management 36:332-345.

7. Ibrahim, I. M., D. H. Abdelmalek, M. E. Elshahat, and A. A. Elfiky. 2020. COVID-19 Spike-host cell receptor GRP78 binding site prediction. The Journal of infection.

8. Lee, H. S., S. Jo, H. S. Lim, and W. Im. 2012. Application of binding free energy calculations to prediction of binding modes and affinities of MDM2 and MDMX inhibitors. Journal of chemical information and modeling 52:1821-1832.

9. Li, F. 2015. Receptor recognition mechanisms of coronaviruses: a decade of structural studies. Journal of virology 89:1954-1964.

10. Liu, Z., X. Xiao, X. Wei, J. Li, J. Yang, H. Tan, J. Zhu, Q. Zhang, J. Wu, and L. Liu. 2020. Composition and divergence of coronavirus spike proteins and host ACE2 receptors predict potential intermediate 
hosts of SARS-CoV-2. Journal of medical virology.

11. Métifiot, M., C. Marchand, and Y. Pommier. 2013. HIV integrase inhibitors: 20-year landmark and challenges. Advances in pharmacology (San Diego, Calif.) 67:75-105.

12. Qin, C., L. Zhou, Z. Hu, S. Zhang, S. Yang, Y. Tao, C. Xie, K. Ma, K. Shang, W. Wang, and D. S. Tian. 2020. Dysregulation of immune response in patients with COVID-19 in Wuhan, China. Clinical infectious diseases : an official publication of the Infectious Diseases Society of America.

13. Rao, P. K. 2009. CCR5 inhibitors: Emerging promising HIV therapeutic strategy. Indian journal of sexually transmitted diseases and AIDS 30:1-9.

14. Rathbun, R. C., S. M. Lockhart, M. M. Miller, and M. D. Liedtke. 2014. Dolutegravir, a secondgeneration integrase inhibitor for the treatment of HIV-1 infection. The Annals of pharmacotherapy 48:395-403.

15. Shah, B. M., J. J. Schafer, and J. A. Desimone, Jr. 2014. Dolutegravir: a new integrase strand transfer inhibitor for the treatment of HIV. Pharmacotherapy 34:506-520.

16. Walls, A. C., Y. J. Park, M. A. Tortorici, A. Wall, A. T. McGuire, and D. Veesler. 2020. Structure, Function, and Antigenicity of the SARS-CoV-2 Spike Glycoprotein. Cell.

17. Warde-Farley, D., S. L. Donaldson, O. Comes, K. Zuberi, R. Badrawi, P. Chao, M. Franz, C. Grouios, F. Kazi, C. T. Lopes, A. Maitland, S. Mostafavi, J. Montojo, Q. Shao, G. Wright, G. D. Bader, and Q. Morris. 2010. The GeneMANIA prediction server: biological network integration for gene prioritization and predicting gene function. Nucleic acids research 38:W214-220.

18. Wensing, A. M., N. M. van Maarseveen, and M. Nijhuis. 2010. Fifteen years of HIV Protease Inhibitors: raising the barrier to resistance. Antiviral research 85:59-74.

19. Xu, H., L. Zhong, J. Deng, J. Peng, H. Dan, X. Zeng, T. Li, and Q. Chen. 2020. High expression of ACE2 receptor of 2019-nCoV on the epithelial cells of oral mucosa. International journal of oral science 12:8.

20. Yan, R., Y. Zhang, Y. Li, L. Xia, Y. Guo, and Q. Zhou. 2020. Structural basis for the recognition of the SARS-CoV-2 by full-length human ACE2. Science (New York, N.Y.).

21. Zhang, H., J. M. Penninger, Y. Li, N. Zhong, and A. S. Slutsky. 2020. Angiotensin-converting enzyme 2 (ACE2) as a SARS-CoV-2 receptor: molecular mechanisms and potential therapeutic target. Intensive care medicine.

22. Zheng, M., and L. Song. 2020. Novel antibody epitopes dominate the antigenicity of spike glycoprotein in SARS-CoV-2 compared to SARS-CoV. Cellular \& molecular immunology.

23. Zou, X., K. Chen, J. Zou, P. Han, J. Hao, and Z. Han. 2020. Single-cell RNA-seq data analysis on the receptor ACE2 expression reveals the potential risk of different human organs vulnerable to 2019nCoV infection. Frontiers of medicine.

\section{Declarations}

Acknowledgments: 
We would like to thank the Dr. Vijayalakshmi Venkatesan Scientist G, National Institute of Nutrition and Director, National Institute of Technology for extending all the help to carry out this work and, Indian Council of Medical Research for Providing ICMR-Post Doctoral Support Fellowship.

\section{Funding: not applicable}

Author information: Authors: Santhoshi Rani Nanchari ${ }^{1}$, Shyam Perugu ${ }^{2 *}$

${ }^{1}$ Department of Stem cell research and Biochemistry, National Institute of Nutrition

2 Department of Biotechnology, National Institute of Technology Warangal.

List of authors with mail ids:

Santhoshi Rani Nanchari: santhoshi.genetics@gmail.com

Shyam Perugu: shyamperugu@nitw.ac.in

Corresponding author:

DR PERUGU SHYAM

ASSISTANT PROFESSOR

DEPARTMENT OF BIOTECHNOLOGY

NATIONAL INSTITUTE OF TECHNOLOGY, WARANGAL

WARANGAL-500604, TELANGANA, INDIA.

9948561761

\section{Authors Contributions:}

SRN contributed in writing the manuscript, selection of ligands and design of the study and PS contributed in in silico analysis, data analysis, and interpretation of the results and critical revision of the manuscript. 


\section{Ethics declarations Ethics approval and consent to participate}

Not applicable.

\section{Consent for publication}

Not applicable.

Conflicts of interest:

There is no conflict of interest between the authors.

\section{Tables}

Table 1: Molecular docking interactions with receptor [Crystal Structure of COVID-19 main protease in complex with Z18197050 (5r80)] and ligand (Stranded drugs).

\begin{tabular}{|c|c|c|c|c|c|}
\hline $\begin{array}{c}\text { Receptor } \\
\text { (5R8O) }\end{array}$ & Ligand Name & Receptor interaction atoms & Ligand Atoms & $\begin{array}{c}\text { H-bond Distance } \\
\left(\mathrm{A}^{\mathrm{o}}\right)\end{array}$ & $\begin{array}{c}\text { Docking score } \\
\text { (Kcal/mol) }\end{array}$ \\
\hline \multirow{16}{*}{$5 \mathrm{R} 80$} & Atazanavir & GLU166-O & $\mathrm{NH}$ & 3.28 & -78.993 \\
\hline & \multirow[t]{3}{*}{ Doravirine } & THR25-OG1 & $\mathrm{NH}$ & 2.55 & \multirow[t]{3}{*}{-86.864} \\
\hline & & ASN142-OD1 & $\mathrm{NH}$ & 3.16 & \\
\hline & & CYS44-O & $\mathrm{NH}$ & 3.04 & \\
\hline & \multirow[t]{2}{*}{ Emtricitabine } & THR190-O & $\mathrm{NH}$ & 2.96 & \multirow[t]{2}{*}{-84.316} \\
\hline & & GLU192-NE1 & $\mathrm{O}$ & 3.10 & \\
\hline & \multirow[t]{2}{*}{ Entravirine } & THR190-O & $\mathrm{NH}$ & 3.04 & \multirow[t]{2}{*}{-76.688} \\
\hline & & GLN189-OE1 & & 3.19 & \\
\hline & \multirow[t]{2}{*}{ Raltegravir } & GLU166-O & $\mathrm{NH}$ & 2.78 & \multirow[t]{2}{*}{-83.660} \\
\hline & & THR190-NH & $\mathrm{O}$ & 3.23 & \\
\hline & \multirow[t]{3}{*}{ Tenofavir Disoproxil } & GLU166-O & $\mathrm{NH}$ & 2.25 & \multirow[t]{3}{*}{-5.375} \\
\hline & & GLU166-O & $\mathrm{NH}$ & 3.18 & \\
\hline & & GLU166-NH & $\mathrm{O}$ & 3.13 & \\
\hline & \multirow[t]{3}{*}{ Zidovudine } & THR190-O & $\mathrm{H}$ & 3.04 & \multirow[t]{3}{*}{-78.364} \\
\hline & & GLN189-N & $\mathrm{H}$ & 3.09 & \\
\hline & & GLU166-N & $\mathrm{H}$ & 3.08 & \\
\hline
\end{tabular}

Table.2. Molecular interactions with receptor [Nsp9 replicase protein of COVID-19 (6W4B)] and ligand (Stranded drugs). 


\begin{tabular}{|c|c|c|c|c|c|}
\hline $\begin{array}{l}\text { Receptor } \\
\text { (6W4B) }\end{array}$ & Ligand Name & Receptor interaction atoms & Ligand Atoms & $\begin{array}{l}\text { H-bond Distance } \\
\left(\mathrm{A}^{\mathrm{o}}\right)\end{array}$ & $\begin{array}{c}\text { Docking score } \\
\text { (Kcal/mol) }\end{array}$ \\
\hline \multirow{19}{*}{ 6W4B } & \multirow[t]{3}{*}{ Atazanavir } & GLN50-NE2 & $\mathrm{NH}$ & 2.74 & \multirow[t]{3}{*}{-92.993} \\
\hline & & MET1-O & $\mathrm{NH}$ & 2.98 & \\
\hline & & ASN3-N & $\mathrm{O}$ & 3.31 & \\
\hline & \multirow[t]{2}{*}{ Doravirine } & THR35-OD1 & $\mathrm{NH}$ & 2.86 & \multirow[t]{2}{*}{-89.864} \\
\hline & & ALA9-O & $\mathrm{NH}$ & 3.97 & \\
\hline & \multirow[t]{2}{*}{ Emtricitabine } & ASP61-NH & $\mathrm{O}$ & 3.10 & \multirow[t]{2}{*}{-79.316} \\
\hline & & ASP61-OD2 & $\mathrm{NH}$ & 3.15 & \\
\hline & \multirow[t]{3}{*}{ Entravirine } & SER6-O & $\mathrm{NH}$ & 2.61 & \multirow[t]{3}{*}{-90.350} \\
\hline & & SER6-O & $\mathrm{NH}$ & 2.65 & \\
\hline & & VAL8-O & $\mathrm{NH}$ & 2.84 & \\
\hline & \multirow[t]{2}{*}{ Hydroxy chloroquine } & Thr68-OG1 & $\mathrm{NH}$ & 2.81 & \multirow[t]{2}{*}{-80.325} \\
\hline & & ARG40-O & $\mathrm{NH}$ & 3.11 & \\
\hline & \multirow[t]{2}{*}{ Raltegravir } & ARG56-NH2 & $\mathrm{O}$ & 2.74 & \multirow[t]{2}{*}{-91.157} \\
\hline & & ASP27-OD1 & $\mathrm{N}$ & 2.77 & \\
\hline & \multirow[t]{2}{*}{ Tenofavir Disoproxil } & LYS59-O & $\mathrm{NH}$ & 3.79 & \multirow[t]{2}{*}{-88.375} \\
\hline & & PRO58-O & $\mathrm{NH}$ & 2.61 & \\
\hline & Tipranavir & GLN12-N & $\mathrm{O}$ & 3.40 & -71.021 \\
\hline & \multirow[t]{2}{*}{ Zidovudine } & PRO58-O & $\mathrm{NH}$ & 2.59 & \multirow[t]{2}{*}{-85.364} \\
\hline & & SER60-N & $\mathrm{O}$ & 3.09 & \\
\hline
\end{tabular}

Table.3. Molecular interactions with receptor [COVID-19 main protease with unliganded active site (6Y84)] and ligand (Stranded drugs). 


\begin{tabular}{|c|c|c|c|c|c|}
\hline $\begin{array}{l}\text { Receptor } \\
\text { (6Y84) }\end{array}$ & Ligand Name & Receptor interaction atoms & Ligand Atoms & $\begin{array}{c}\text { H-bond Distance } \\
\qquad\left(\mathrm{A}^{\mathrm{o}}\right)\end{array}$ & $\begin{array}{c}\text { Docking score } \\
\text { (Kcal/mol) }\end{array}$ \\
\hline \multirow{25}{*}{$6 Y 84$} & Atazanavir & LEU272-O & $\mathrm{NH}$ & 3.29 & -77.193 \\
\hline & \multirow[t]{5}{*}{ Doravirine } & PHE185-O & $\mathrm{NH}$ & 2.97 & \multirow[t]{5}{*}{-89.415} \\
\hline & & PHE185-O & $\mathrm{NH}$ & 2.98 & \\
\hline & & ASP187-O & $\mathrm{NH}$ & 2.92 & \\
\hline & & ARG40-NH2 & $\mathrm{O}$ & 2.61 & \\
\hline & & ARG40-NH2 & $\mathrm{O}$ & 3.10 & \\
\hline & \multirow[t]{3}{*}{ Emtricitabine } & LEU141-O & $\mathrm{NH}$ & 3.12 & \multirow[t]{3}{*}{-89.316} \\
\hline & & SER144-OG & $\mathrm{NH}$ & 2.91 & \\
\hline & & CYS145-N & $\mathrm{O}$ & 2.90 & \\
\hline & \multirow[t]{2}{*}{ Entravirine } & THR26-O & $\mathrm{NH}$ & 3.09 & \multirow[t]{2}{*}{-89.081} \\
\hline & & SER144-OG & $\mathrm{NH}$ & 2.63 & \\
\hline & \multirow[t]{2}{*}{ Hydroxy chloroquine } & MET6-O & $\mathrm{NH}$ & 3.38 & \multirow[t]{2}{*}{-83.214} \\
\hline & & VAL303-O & $\mathrm{NH}$ & 3.66 & \\
\hline & \multirow[t]{4}{*}{ Raltegravir } & TYR154-NH & $\mathrm{O}$ & 2.57 & \multirow[t]{4}{*}{-89.241} \\
\hline & & VAL303-O & $\mathrm{NH}$ & 2.61 & \\
\hline & & VAL303-O & $\mathrm{NH}$ & 3.00 & \\
\hline & & ILE132-O & $\mathrm{NH}$ & 3.10 & \\
\hline & \multirow[t]{2}{*}{ Tenofavir Disoproxil } & THR25-OG1 & $\mathrm{NH}$ & 3.31 & \multirow[t]{2}{*}{-68.715} \\
\hline & & LEU167-N & $\mathrm{O}$ & 4.30 & \\
\hline & \multirow[t]{3}{*}{ Tipranavir } & ASN142-ND2 & $\mathrm{O}$ & 3.11 & \multirow[t]{3}{*}{-76.325} \\
\hline & & THR26-O & $\mathrm{N}$ & 3.06 & \\
\hline & & GLY143-N & $\mathrm{O}$ & 3.04 & \\
\hline & \multirow[t]{3}{*}{ Zidovudine } & PHE140-O & $\mathrm{NH}$ & 2.66 & \multirow[t]{3}{*}{-89.384} \\
\hline & & GLY143-N & $\mathrm{O}$ & 2.73 & \\
\hline & & CYS145-N & $\mathrm{O}$ & 2.90 & \\
\hline
\end{tabular}

Table.4. Molecular interactions with receptor [coronavirus attachment to sialic acid receptors- Apo-HCoV-OC43 S (6OHW)] and ligand (Stranded drugs). 


\begin{tabular}{|c|c|c|c|c|c|}
\hline $\begin{array}{l}\text { Receptor } \\
\text { (6OHW) }\end{array}$ & Ligand Name & Receptor interaction atoms & Ligand Atoms & $\begin{array}{c}\text { H-bond Distance } \\
\left(\mathrm{A}^{\mathrm{o}}\right)\end{array}$ & $\begin{array}{c}\text { Docking score } \\
\text { (Kcal/mol) }\end{array}$ \\
\hline \multirow{20}{*}{$6 \mathrm{OHW}$} & Atazanavir & THR192-OG1 & $\mathrm{NH}$ & 3.10 & -75.354 \\
\hline & \multirow[t]{2}{*}{ Doravirine } & ASN133-ND2 & $\mathrm{O}$ & 2.95 & \multirow[t]{2}{*}{-87.354} \\
\hline & & ASN167-ND2 & $\mathrm{O}$ & 3.13 & \\
\hline & \multirow[t]{3}{*}{ Emtricitabine } & SER196-OG & $\mathrm{NH}$ & 2.98 & \multirow[t]{3}{*}{-89.819} \\
\hline & & GLN165-OE1 & $\mathrm{NH}$ & 2.60 & \\
\hline & & ASN167-ND2 & $\mathrm{O}$ & 3.04 & \\
\hline & \multirow[t]{4}{*}{ Entravirine } & GLN165-OE1 & $\mathrm{NH}$ & 2.57 & \multirow[t]{4}{*}{-84.324} \\
\hline & & GLN165-OE1 & $\mathrm{NH}$ & 3.10 & \\
\hline & & VAL194-O & $\mathrm{NH}$ & 3.11 & \\
\hline & & THR131-O & $\mathrm{NH}$ & 3.14 & \\
\hline & \multirow[t]{2}{*}{ Raltegravir } & GLY193-N & $\mathrm{NH}$ & 2.74 & \multirow[t]{2}{*}{-90.189} \\
\hline & & THR192-N & $\mathrm{N}$ & 2.66 & \\
\hline & \multirow[t]{3}{*}{ Tenofavir Disoproxil } & VAL194-O & $\mathrm{NH}$ & 2.64 & \multirow[t]{3}{*}{-91.355} \\
\hline & & VAL194-O & $\mathrm{NH}$ & 2.85 & \\
\hline & & GLY193-N & $\mathrm{O}$ & 3.23 & \\
\hline & \multirow[t]{2}{*}{ Tipranavir } & ASN167-ND2 & $\mathrm{H}$ & 2.98 & \multirow[t]{2}{*}{-90.395} \\
\hline & & VAL194-O & $\mathrm{NH}$ & 3.02 & \\
\hline & \multirow[t]{3}{*}{ Zidovudine } & ASP191-OD1 & $\mathrm{H}$ & 2.66 & \multirow[t]{3}{*}{-88.311} \\
\hline & & THR192-N & $\mathrm{H}$ & 3.12 & \\
\hline & & ASN167-ND2 & $\mathrm{H}$ & 3.10 & \\
\hline
\end{tabular}

\section{Figures}




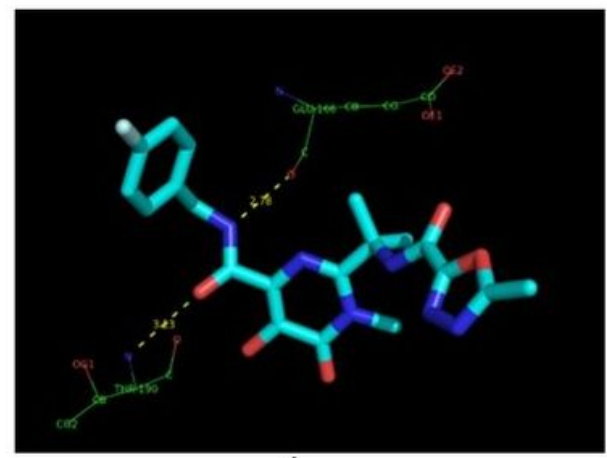

A

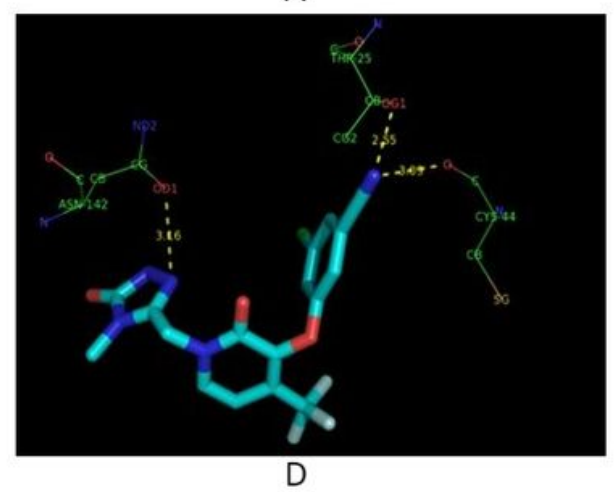

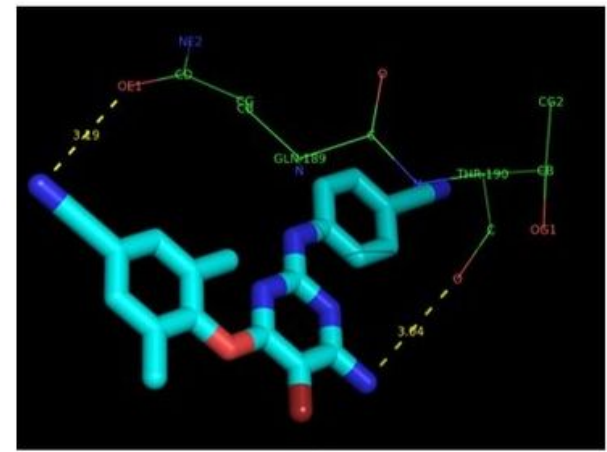

C

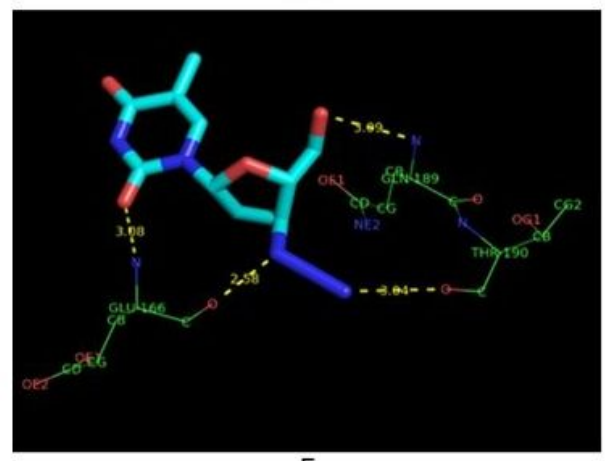

$\mathrm{F}$

\section{Figure 1}

Molecular docking interactions with receptor [Crystal Structure of COVID-19 main protease in complex with Z18197050 (5r80)] and ligand (Stranded drugs). A: Doravirine B: Emtricitabine C: Etravirine D: Raltegravir E: Tenofavir Disoproxil F: Zidovudine
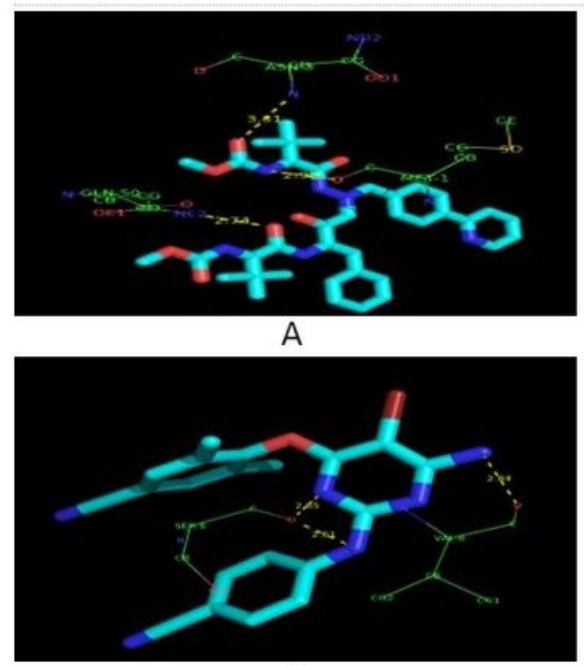

D

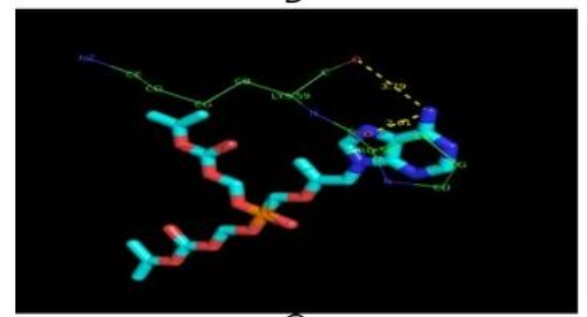

G
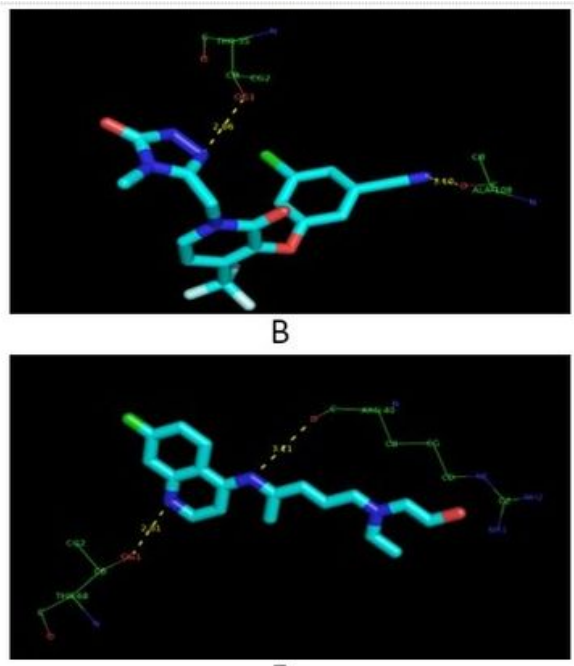

$\mathrm{E}$

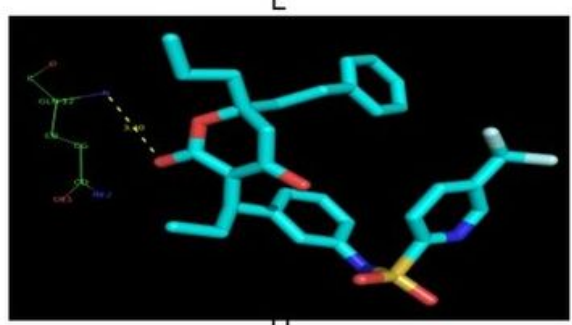

H

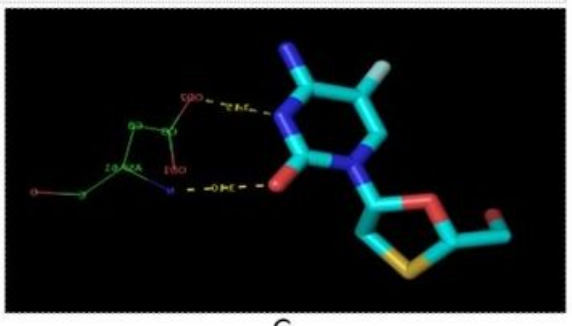

C

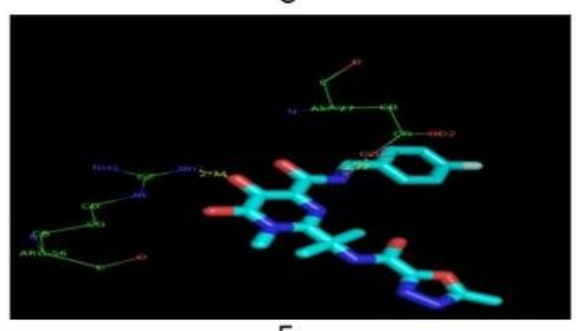

F

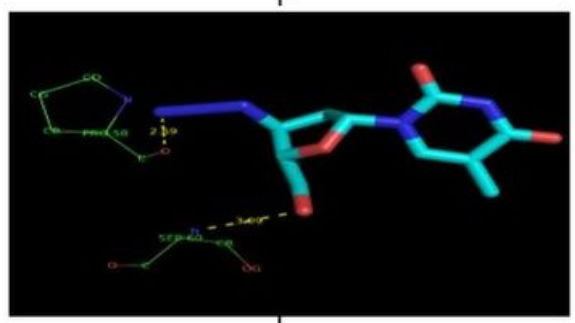

|

Figure 2 
Molecular interactions with receptor [Nsp9 replicase protein of COVID-19 (6W4B)] and ligand (Stranded drugs). A: Atazanavir B: Doravirine C: Emtricitabine D: Etravirine E: Hydroxychloroquine F: Raltegravir G: Tenofavir Disoproxil H: Tipranavir I: Zidovudine

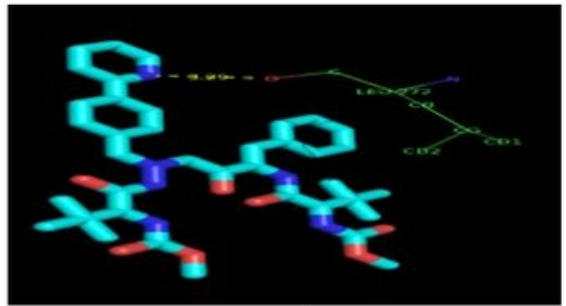

A
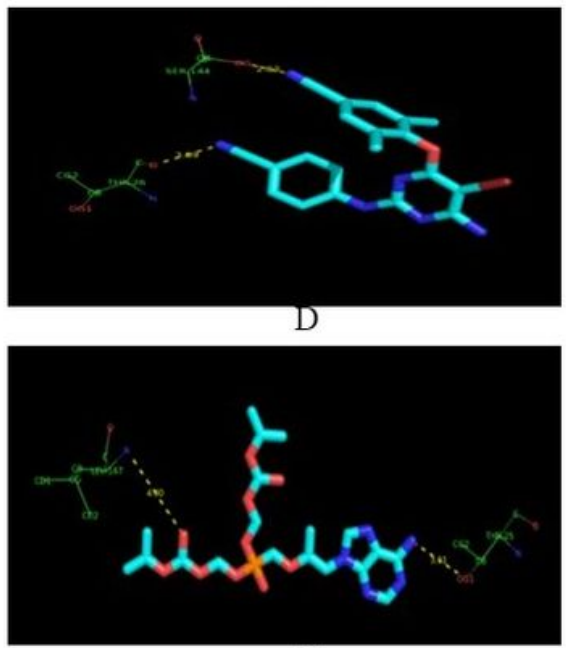

G

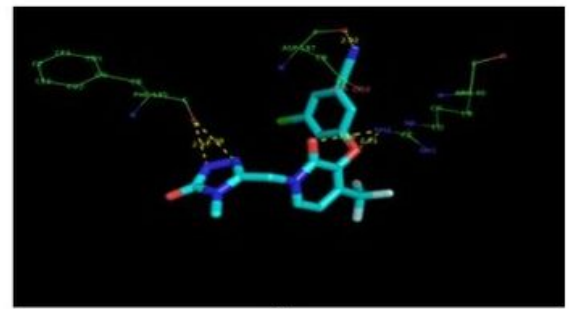

B
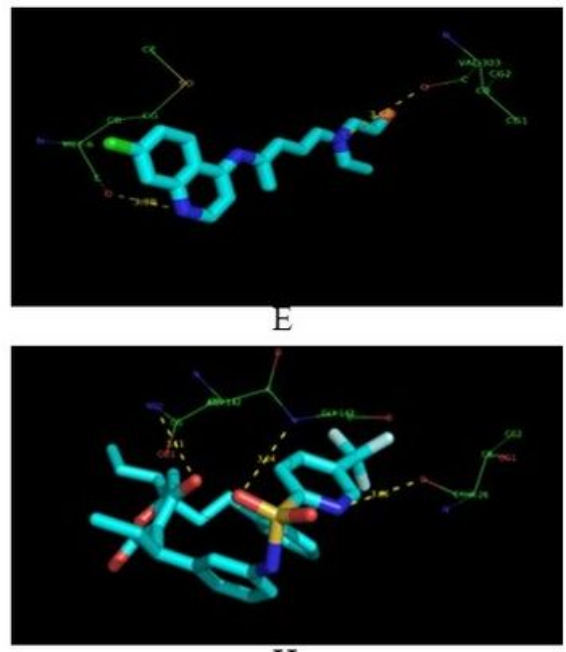

H

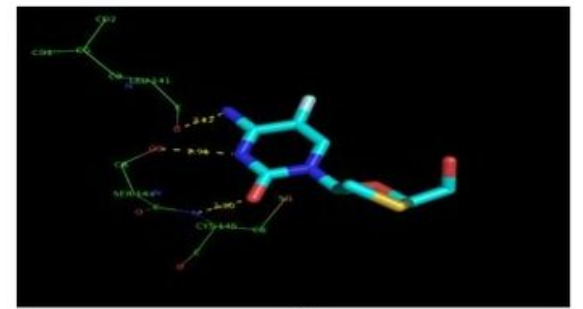

C
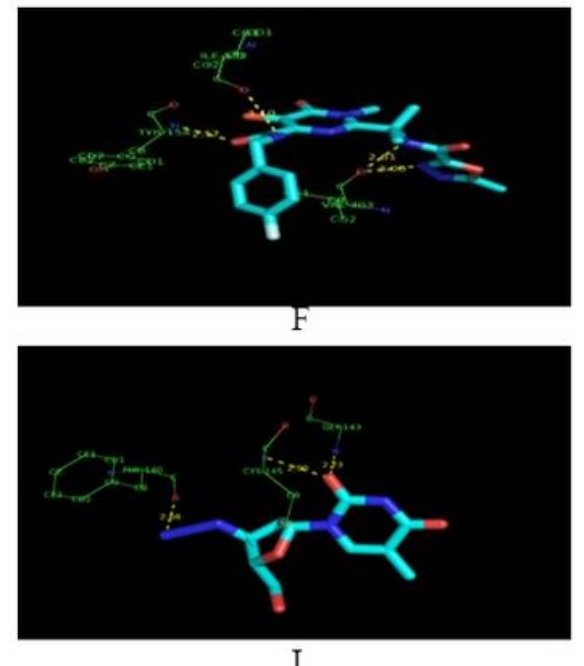

Figure 3

Molecular interactions with receptor [COVID-19 main protease with unliganded active site (6Y84)] and ligand (Stranded drugs). A: Atazanavir B: Doravirine C: Emtricitabine D: Etravirine E: Hydroxychloroquine F: Raltegravir G: Tenofavir Disoproxil H: Tipranavir I: Zidovudine 


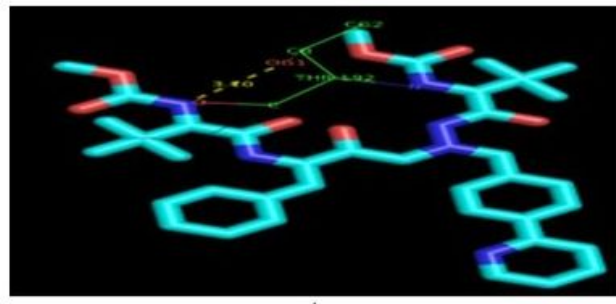

A

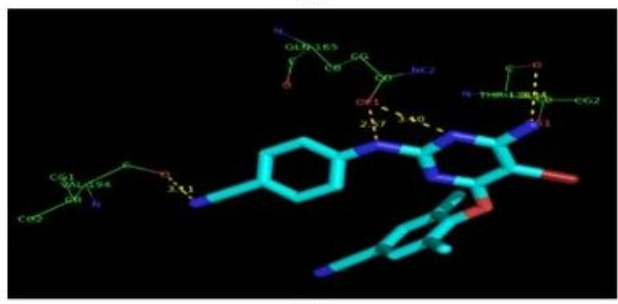

D

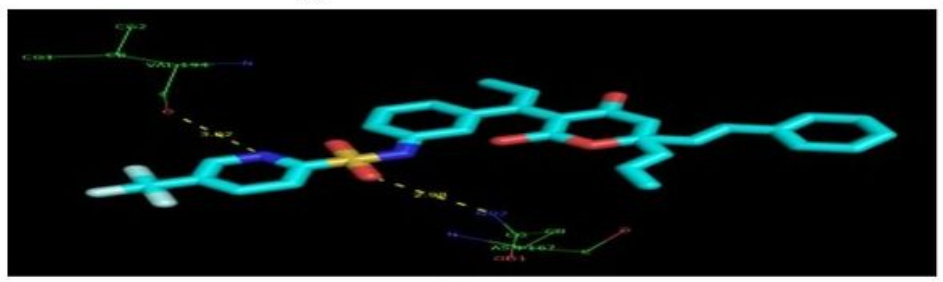

G

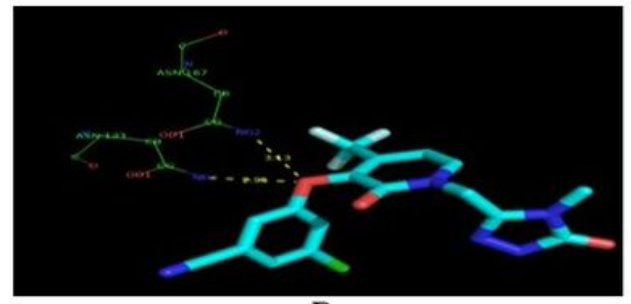

B

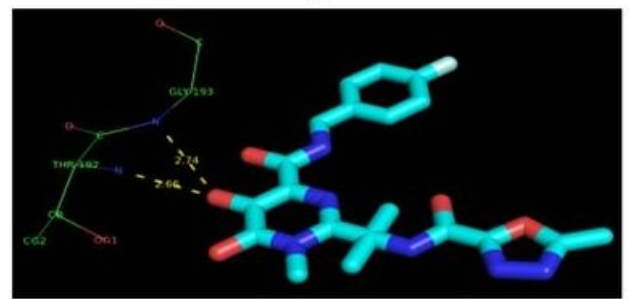

E

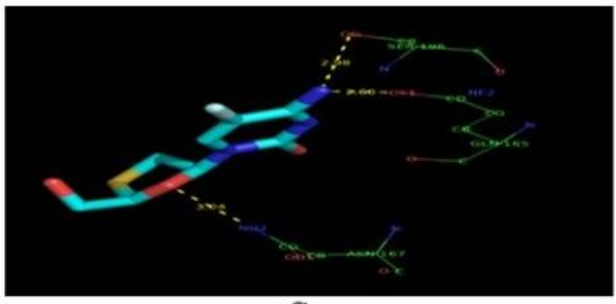

C

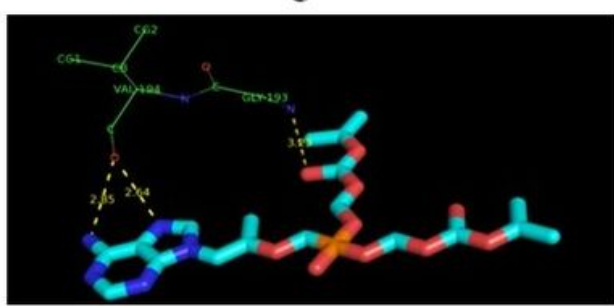

F

\section{Figure 4}

Molecular interactions with receptor [coronavirus attachment to sialic acid receptors- Apo-HCoV-OC43 S $(6 \mathrm{OHW})]$ and ligand (Stranded drugs). A: Atazanavir B: Doravirine C: Emtricitabine D: Etravirine E: Raltegravir F: Tenofavir Disoproxil G: Tipranavir H: Zidovudine

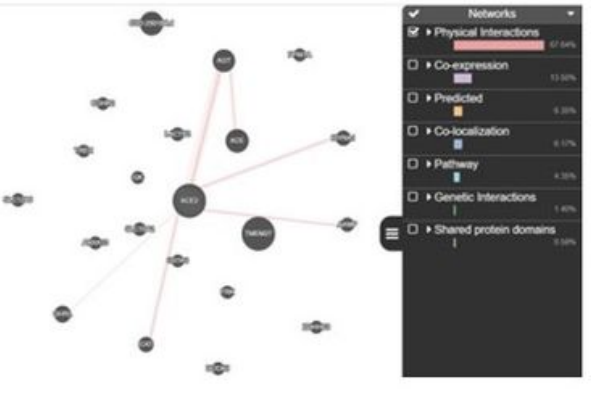

A

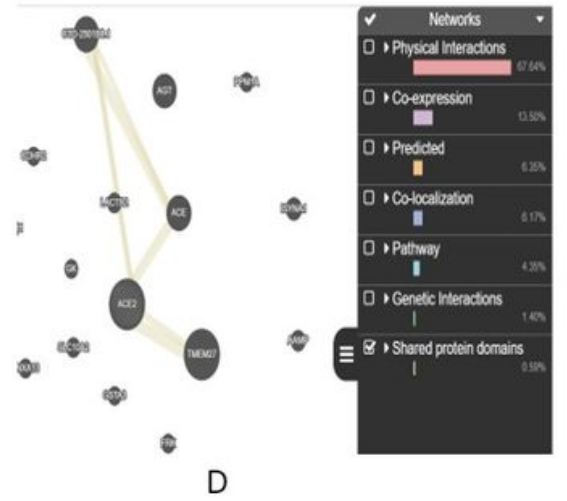

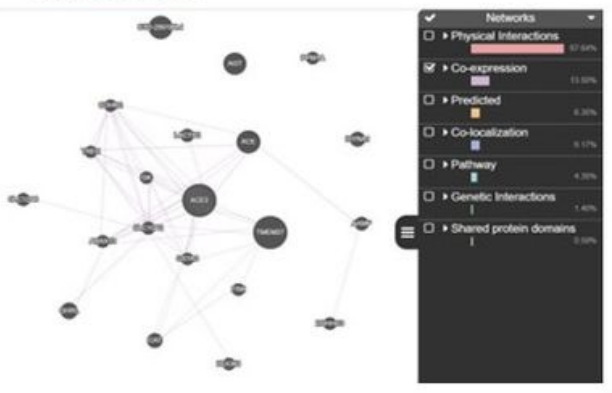

B

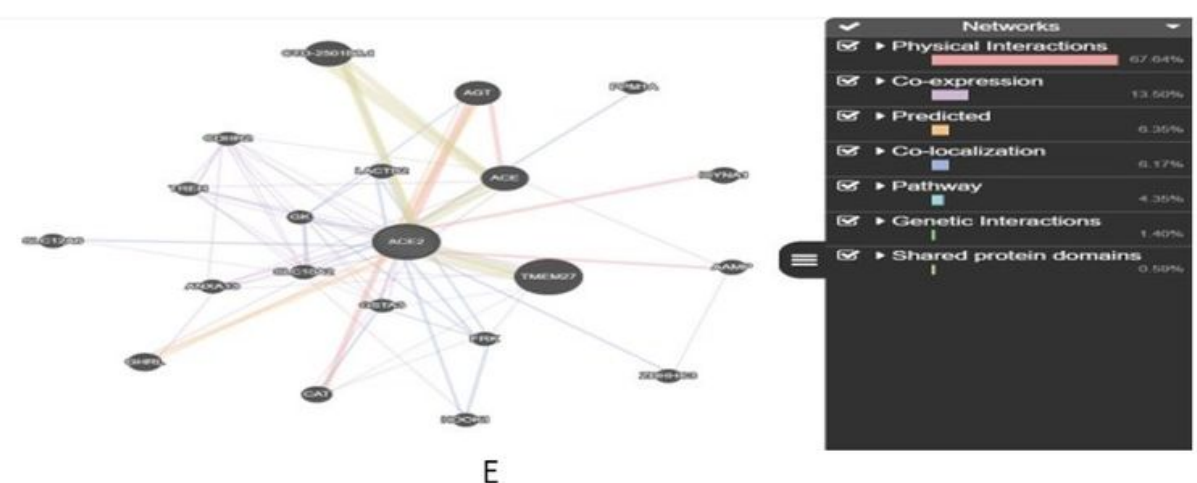

Figure 5 
Network analysis for gene and protein (Genemania) of ACE2 A:Physical interaction B: Co-expession C: Colocalization D:Shared protein-protein domains E: Network of ACE2

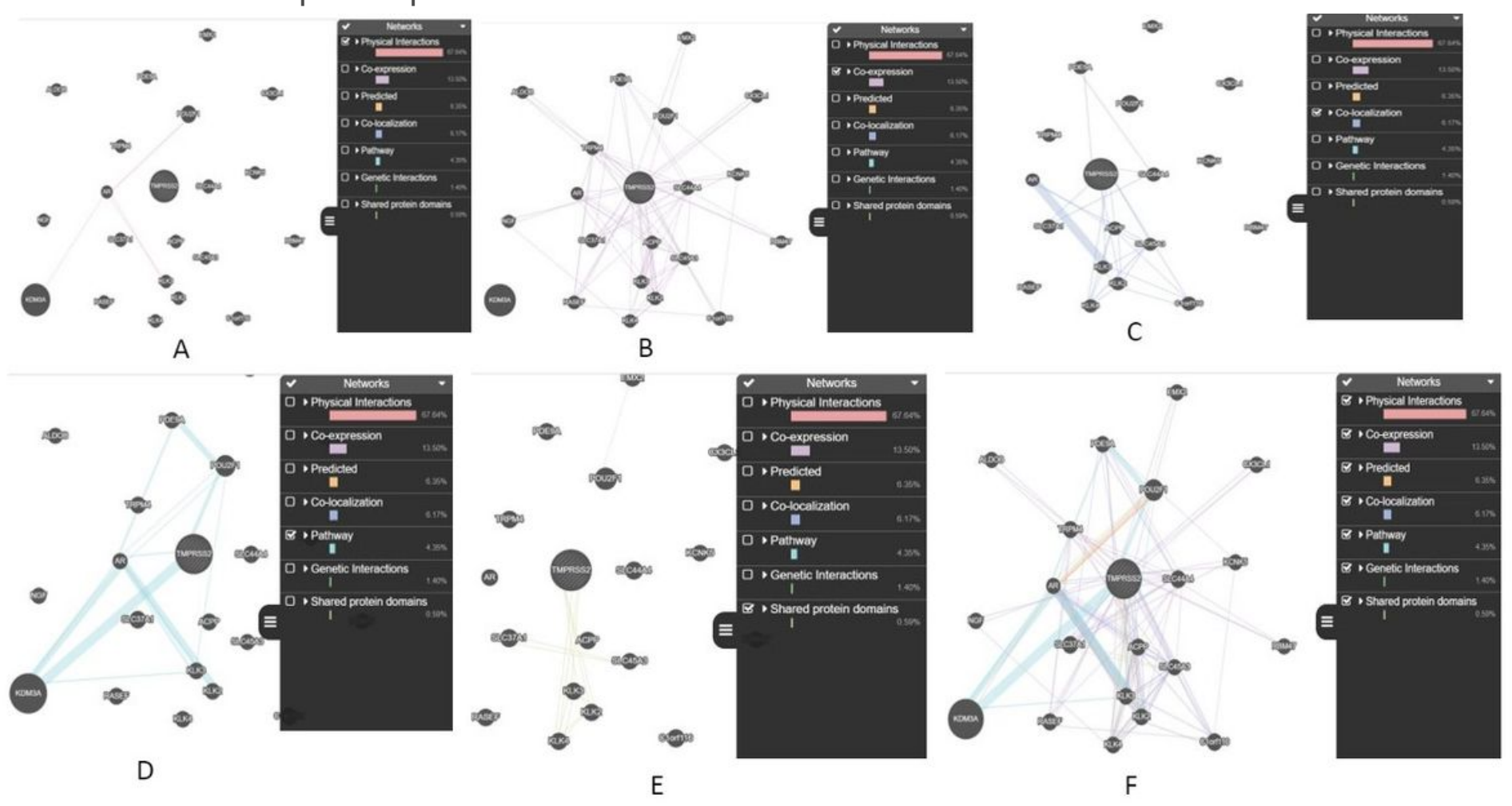

\section{Figure 6}

Network analysis for gene and protein (Genemania) of TMPRSS2 A:Physical interaction B: Co-expession C: Co-localization D: Same Pathway E:Shared protein-protein domains F: Network of TMPRSS2 